Research Journal of Applied Sciences 13 (5): 285-293, 2018

ISSN: $1815-932 \mathrm{X}$

(C) Medwell Journals, 2018

\title{
Convective Instability Indices and Thermo-Dynamical Parameter for Forecasting Thunderstorms Occurrences over Kano, Nigeria
}

\author{
${ }^{1,2}$ Orimoloye Israel Ropo and ${ }^{2}$ Adefisan Elijah Adesanya \\ ${ }^{1}$ Department of Geography and Environmental Science, University of Fort Hare, \\ Private Bag X1314, Eastern Cape Province, 5700 Alice, South Africa \\ ${ }^{2}$ Department of Meteorology and Climate Science, Federal University of Technology, Akure, Nigeria
}

\begin{abstract}
The thunderstorms forecasting has been identified by many forecasters as an unusually difficult problem deserving of some special research attention. The study investigated the roles of Convective Instability (CI) Indices and Thermo-dynamical Parameter (SITP) on thunderstorms occurrences and hence, determined the threshold values of these SITPs necessary for thunderstorm and occurrences and used for short-range forecasting of thunderstorm occurrence over Kano, Nigeria. Daily upper air data and hourly significant weather for August and September in years, 2012 and 2013 obtained from the archive of Nigerian meteorology agency were used. The study uses the concept of "a $2 \times 2$ contingency table" for analysing thunderstorm occurrence and obtained some simple skill scores such as Accuracy (AC), Bias (B), Probability of Detection (POD), False Alarm Ratio (FAR), Probability of False Detection (POFD) and Success Ratio (SR). The study established that if Cl between 925 and $850 \mathrm{mb}$ pressure levels is $\geq 100 \mathrm{hpa}^{-1}$ and CAPE is $\geq 2500 \mathrm{~J} / \mathrm{kg}$ simultaneously, the probability of thunderstorm occurrence is $70 \%$. It means that success ratio of a $2 \times 2$ contingency table is $68 \%$ and the accuracy is about $74 \%$ and the FAR is $29 \%$. The result has finally shown that short range-range forecast of the occurrence of thunderstorm and squall line is possible with the availability of upper air data.
\end{abstract}

Key words: Thunderstorm, forecasting, occurrence, contingency table, convective stability, availability

\section{INTRODUCTION}

A thunderstorm is defined as a storm with a lightning sound know as thunder. This is usually produced by the cumulonimbus cloud and when this occurs it is also produced gusty winds, heavy rain sometimes it can be accompanied by hail. Thunderstorm occurrence is usually of short lifespan, sometimes $2 \mathrm{~h}$ for any one storm. Sometimes thunderstorm can be as a result of atmospheric instability loosely an overturning of air parcel or layer in order to achieve more density stratification. Thunderstorm at times can be so, hazardous which inflict huge damages on life and properties as well as socio-economic (Paulikas and Ashley, 2011; Serkov et al., 2015). Thunderstorm can be easily identified from other storms by its strong convective in its formation stage and a fervent downdraft in a column of precipitation marks its dissipating stage. Thunderstorm can build up to altitudes of about $12-15 \mathrm{~km}$ in mid-latitudes and it can go higher than that in the tropics, only the great stability of the lower stratosphere can stop its growth upward. In West Africa like other places in the world' weather observing guidelines, a thunderstorm is usually reported whenever thunder is heard at the designated station, its reported on regularly scheduled observations and whenever a sound of thunder is heard within $15 \mathrm{~min}$ ahead the observation, thunderstorm share a common lifting mechanism with squal line sometimes refer to as a line of thunderstorm. More so, lifting mechanism has a tendency to occur in a band, front, large outflow boundaries, gravity waves and isentropic are examples of those bands lifting associated with Conditional Symmetric Instability (CSI). Thunderstorms occur year-round in some regions in mid-latitudes it developed commonly in the Spring, Summer and fall but in arctic regions, thunderstorms occur occasionally in Summer (Budnuka, 2015; Tinmaker et al., 2010). The base of the clouds ranging from about 7-13 km but sometimes it can extend above $19 \mathrm{~km}$, cooling in the updraft as upward force creates an inertial updraft can result in condensation and the beginning of cumulus clouds. Updraft can becomes self-sustaining as the condensation releases latent heat which partially offsets cooling in the saturated updraft and add more to buoyancy within the cloud (Ekwe et al.,

Corresponding Author: Orimoloye Israel Ropo, Department of Geography and Environmental Science, University of Fort Hare, Private Bag X1314, Eastern Cape Province, 5700 Alice, South Africa 


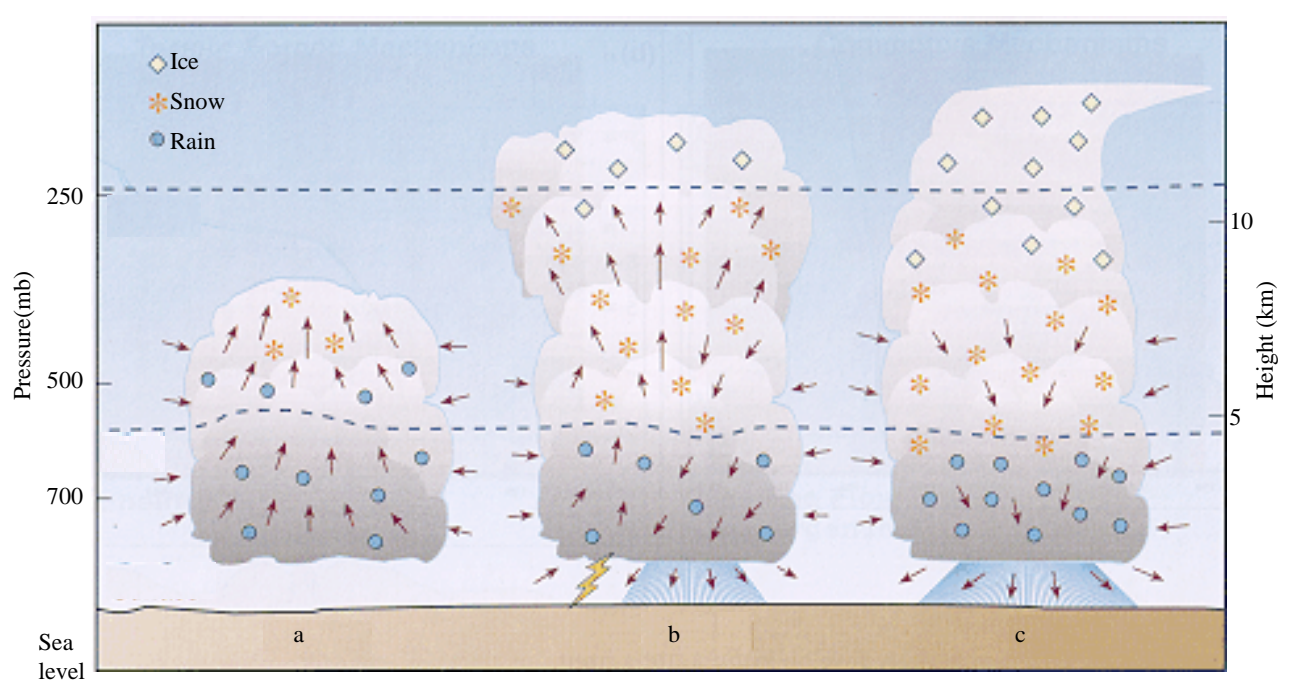

Fig. 1: Stages of life cycle of thunderstorms: a) Cumulus stage; b) Mature stage and c) Decaying stage. Arrows indicate wind directions

2014) and also when the air current is unstable and there is formation of moisture around rain clouds generates electrical charges together with thunderstorm and all thunderstorm pass through a life cycle from its initial stage through the maturity and into dissipation stage (Fig. 1).

Adelekan (1998) examined the spatial and temporal in thunderstorm rainfall variation over Nigeria using daily rainfall data combine with weather information over nineteen synoptic weather stations and noticed that the dry season rainfall distribution pattern as a result thunderstorm revealed decrease from South to towards North and it's also similar to total rainfall pattern in Nigeria. The rainfall distribution reached its peak in the wet season between July and September and it was discovered that the thunderstorms rainfall increases Northwards (Omotosho et al., 1985; Mugalavai et al., 2008). Thunderstorms rainfall is one of the major forms of convective rainfall over the study area and Nigeria at large. Thunderstorm and squall line rainfall is a major form of convective rainfall over the study area and Nigeria at large. Thunderstorms contribute to about $70 \%$ of rainfall in wet season in the South, the significance of thunderstorms lies in the fact that it contributes to soil erosion, land degradation and flooding episodes as a result of its high intensity and torrential features (Berz et al., 2001; Wieczorek et al., 2001). Akinsanola and Ogunjobi (2014) in their study of analysis of rainfall and temperature in Nigeria, air temperature $\left({ }^{\circ} \mathrm{C}\right)$ and rainfall $(\mathrm{mm})$ was observed from 25 synoptic stations from 1971-2000 (30 years) suggested that there is decreasing and increasing trends in mean annual precipitation and air temperature, respectively. Several studies have developed some indices for a better thunderstorms forecasting or severe weather (Jacovides and Yonetani, 1990; Huntrieser et al., 1997; DeRubertis, 2006; Wasula et al., 2002). Some of these applications related to static stability indices in Summer time rainfall (Vujovic et al., 2015; You et al., 2015). Low-level moisture instability and convergence in conjunction with upper-level divergence, could produce severe weather as asserted by Taszarek et al. (2017).

Potential or convective instability: This occurs when the dry-midair flow over worm and humid air in the lower region of the troposphere when the dynamic lifting to the mid-levels produces humid or moist lapse rate of airlifted from the lower troposphere and dry adiabatic lapse rate from air that is lifted from the mid-troposphere and the convective stability is released. In one hand, a convectively unstable layer can also be defined as when the parcel's changed in equivalent potential temperature with height and the simple way or method to determine the convective stability of a layer by comparing the equivalent potential temperature of upper boundaries and the lower boundaries of the layer. This can be computed using this information by calculating the change in equivalent potential temperature $(\Theta \mathrm{e})$ with respect to height (z). It should be noted that dry tropical atmosphere is statically stable but when moisture is included then West Africa become convectively unstable (Mounkaila et al., 2015). This fact made to define an instability parameter called convective instability by replacing potential temperature in the former with equivalent potential temperature and is as follow Eq. 1: 


$$
\sigma_{\mathrm{c}}=\frac{1}{\theta \mathrm{e}} \frac{\mathrm{d} \theta \mathrm{e}}{\mathrm{dp}}
$$

When there is a change in the equivalent potential temperature through a layer it implies that there is moisture distribution in the layer and as noted earlier that whenever a layer is convectively unstable is characterized by a humid or moist lower layer and the upper region is dry. The equivalent potential temperature of the lower boundary is higher than the upper layer in a convectively unstable layer. More, so the equivalent potential temperature decreases as it goes up that is with height through the layer. In other hand when a layer is convectively neutral, the potential temperature remain unchanged with respect to height while in a layer that is convectively stable, the potential temperature increases with height. Below is the equation that described the phenomenon:

$$
\begin{aligned}
& \frac{\partial \theta \mathrm{e}}{\partial \mathrm{z}}>0 \Rightarrow \text { Convectively stable } \\
& \frac{\partial \theta \mathrm{e}}{\partial \mathrm{z}}=0 \Rightarrow \text { Convectively neutral } \\
& \frac{\partial \theta \mathrm{e}}{\partial \mathrm{z}}<0 \Rightarrow \text { Convectively unstable }
\end{aligned}
$$

Moreover, lifting of this convectively unstable layer can produce the violent storms which can result in damages of properties and loss of life (Madala et al., 2016).

Atmospheric stability indices and their roles in thunderstorm development: In thunderstorms forecasting, many indices have been used to study the stability nature of the atmosphere and predict the possible development and occurrence of thunderstorm (Moore et al., 2003). Studies have stated that some indices have some shortcoming such that they are not relevant in every region and few attempt have been made to remodel these indices for thunderstorm forecasting most, especially in the North (Moore et al., 2003; Ricard et al., 2012; Azorin-Molina et al., 2014). Some of these indices that were examined are lifted index, Showalter Index, Severe weather index, ADED 1 and ADED 2, total totals, CAPE, CIN (Ricard et al., 2012; Azorin-Molina et al., 2014; Gubenko and Rubinshtein, 2015). Thunderstorms mostly occurred in the months of June through September over the periods that the study was carried out between, 1998 and 2007 and upper air data was used in the analysis. Although, severe thunderstorms are not as common in the North as they are in other parts of the country (Davis and Rogers, 1992; Odekunle et al., 2005) they caused over 100 deaths, 1000 injuries and 1 billion naira in combined property and crop damages (Madala et al., 2016). Consequently, accurate forecast of severe thunderstorms is very important as this will help to reduce the adverse effect that might be resulted from thunderstorm occurrence. More so instability, lift and moisture is the three ingredients which must be available in the atmosphere in order to generate the deep moist convection necessary for severe thunderstorm development (Hart and Cohen, 2016). However, they can be incorporated into decision trees which consider a large number of variables. The threshold value for these indices used in thunderstorm forecasts was developed based on data from the meteorological stations. Previous experience indicates that these threshold values have not been very useful for predicting thunderstorms (Hart and Cohen, 2016). Therefore, the main goal of the study was to investigate how frequently severe thunderstorms occur in the study area. Studies on stability indices have been conducted in different parts of the world, these include Cyprus (Jacovides and Yonetani, 1990), Switzerland (Huntrieser et al., 1997) and US (DeRubertis, 2006). Wasula et al. (2002) developed an equation for predicting the occurrence of thunderstorms and some studies have averaged values for a variety of parameters but have not examined regional differences. Some have subjectively labeled days as having "weak" or strong convection (Fuelberg and Biggar, 1994). Others have counted the number of severe thunderstorms on a particular day in the studied area to assess the level of convection on that day (Wasula et al., 2002). Over the years several method and techniques for thunderstorms prediction have been presented, many of this techniques are large scale system such hurricane which is dominant in a given region. Moore et al. (2003) studied the environment of thunderstorms in a warm season investigated that thunderstorms are always associated with heavy rainfall. Adedokun (1982) developed ADED1 and ADED2 indices for indicating the presence of potential instability within an Inter Tropical Discontinuity (ITD) environment and it was revealed that this index can also be used for precipitation forecasting over West Africa. It was discovered that the first index to be better indicator of stability condition and precipitation non-occurrence while the second index is effective in instability conditions/precipitation-related events (Adedokun, 1982). Both ADED 1 and ADED 2 had a lower percentage of probability of correct forecast. The aim of this study is to use convective instability and convective 
available potential energy for short-range forecast of thunderstorm occurrences in the study area and determine the threshold values of Stability Indices and Thermo-Dynamical Parameters (SITPS) and thunderstorm occurrences.

\section{MATERIALS AND METHODS}

The study area is Kano, Kano is located at latitude $12^{\circ} 03 \mathrm{~N}$ and longitude $8^{\circ} 31^{\prime} \mathrm{E}$. Kano is the capital city of Kano State in the Northern part of Nigeria, the study area is located in the Sahelian geographic part of the South of Sahara and the most populous state out of 36 states in Nigeria (2006 census) with the population of about 9,383,682 million people.

The region features savanna vegetation and a hot, semi-arid climate. Kano has average of about $690 \mathrm{~mm}$ precipitation annually which is always occur in the month of June through September and usually very hot throughout the year but December through February the city is noticeably cooler. Night time temperatures are cool during the months of December, January and February with average low temperatures of $11-14^{\circ} \mathrm{C}$. Gust is a common weather occurrence in the area with speed reaching $45 \mathrm{kt}$. The study area is shown in Fig. 2.

Data collection: Daily upper air data used for this research were obtained through mid-day soundings at Kano for the year, 2012 and 2013. Sounding is performed at MAKIA once a day at $1200 \mathrm{Z}$. Hourly weather observations at Kano for the same day of the months were also utilized for the research. These data were sourced from the archives by the Nigerian Meteorological Agency,
Oshodi and Kano. For the purpose of this study, two software was used Fortran program was written to calculate convective instability and equivalent potential temperature, $\theta \mathrm{e}$ for the appropriate pressure levels and interactive Tephigram Software was used to estimate convective available potential energy.

Methodology: The following methods were used in this research in other to achieve the desired result; Estimate Convective Available Potential Energy (CAPE) and Convective Instability (CI) using interactive Tephigram Software and Fortran programming language, respectively from which threshold values were developed for the purpose of forecasting. CAPE and CI were obtained for two pressure layers (925-850 and $700-500 \mathrm{mb}$, respectively) and these were done for weather-active months in each year. The $2 \times 2$ contingency table was developed for forecast and observed thunderstorm events based on the threshold values of CAPE and CI. CAPE is a measure of instability through the depth of the atmosphere and is related to updraft strength in thunderstorms. Storm Prediction Centre (SPC) forecasters often refer to "weak instability" (CAPE $<1000 \mathrm{~J} / \mathrm{kg}$ ) "moderate instability" (CAPE from 1000-2500 J/kg)

Table 1: Contingency table for forecast and observed parameters (Jolliffe and Stephenson, 2003)

\begin{tabular}{llll}
\hline \multirow{2}{*}{$\begin{array}{l}\text { Thunderstorm } \\
\text { forecst }\end{array}$} & Thunderstorm observed & \\
\hline Yes & Yes & No & Marginal total \\
& $\mathrm{a}$ & $\mathrm{b}$ & $\mathrm{a}+\mathrm{b}$ \\
No & Hits & False alarm & Yes forecast \\
& $\mathrm{c}$ & $\mathrm{d}$ & $\mathrm{c}+\mathrm{d}$ \\
Marginal & Misses & Correct negative & No forecast \\
Total & $\mathrm{a}+\mathrm{c}$ & $\mathrm{b}+\mathrm{d}$ & $\mathrm{a}+\mathrm{b}+\mathrm{c}+\mathrm{d}$ \\
& Yes observed & No observe & $\mathrm{N}$ \\
\hline
\end{tabular}

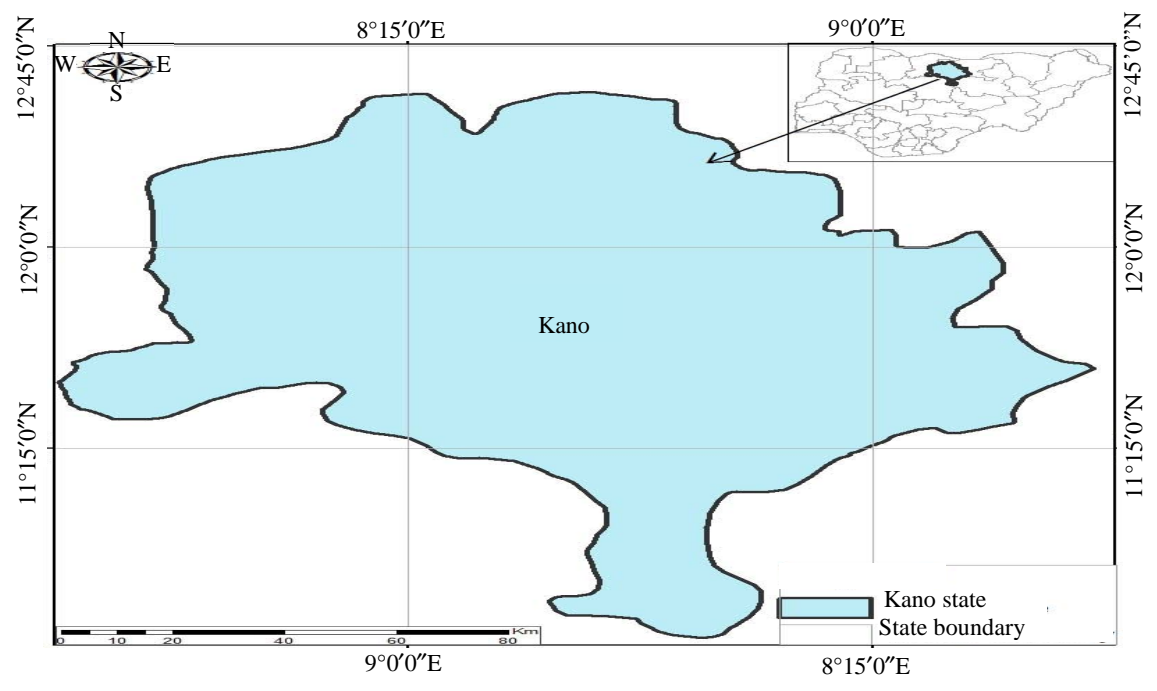

Fig. 2: Map showing the location of study area, Kano, Kano state, Nigeria 
"strong instability" (CAPE from 2500-4000 J/kg) and "extreme instability" (CAPE $>4000 \mathrm{~J} / \mathrm{kg}$ ). The CAPE in this study sounding is about $2500 \mathrm{~J} / \mathrm{kg}$ lifting the "virtual" surface parcel.

The following simple skill scores were used for in this study: Accuracy (AC), Bias (B), Probability of Detection (POD), False Alarm Ratio (FAR), Probability of False Detection (POFD) and Success Ratio (SR):

- Hit: thunderstorm forecast to occur and did occur

- Miss: thunderstorm forecast not to occur but did occur

- False alarm: thunderstorm forecast to occur but did not occur

- Correct negative: thunderstorm forecast not to occur and did not occur

Marginal distribution (N): Total numbers of observed and forecast thunderstorm occurrences and non-occurrences whereas, overall evaluation and analysis are based on Table 1. The formulas for simple skill scores are given as follows:

$$
\text { Accuracy }=\mathrm{ACC}=\frac{\text { Hits }+ \text { Correct negatives }}{\text { Total }}
$$

$0 \leq \mathrm{ACC} \leq 1$, best score: $\mathrm{ACC}=1$, best score $=$ perfect forecast:

$$
\text { Bias }=\mathrm{B}=\frac{\text { Hits }+ \text { Halse alarms }}{\text { Hits }+ \text { Misses }}
$$

$\mathrm{B}=1$ unbiased, $\mathrm{B}<1$ underforecast, $\mathrm{B}>1$ overforecast:

$$
\text { Probabiliy of Detection }=\mathrm{POD}=\frac{\text { Hits }}{\text { Hits }+ \text { Misses }}
$$

$0 \leq \mathrm{POD} \leq 1$, best score: $\mathrm{POD}=1$, best score $\neq$ perfect forecast:

$$
\text { False Alarm Ratio }=\text { FAR }=\frac{\text { False alarms }}{\text { Hits }+ \text { False alarms }}
$$

$0 \leq \mathrm{FAR} \leq 1$, best score: $\mathrm{FAR}=0$, best score $\neq$ perfect forecast. Probability of False Detection:

$$
\text { POFD }=\frac{\text { Hits }}{\text { Hits }+ \text { False alarms }}
$$

$0 \leq \mathrm{POFD} \leq 1$, best score: $\mathrm{POFD}=0$, best score $\neq$ perfect forecast. Success Ratio:

$$
\mathrm{SR}=\frac{\text { False alarms }}{\text { Hits }+ \text { False alarms }}
$$

\section{RESULTS AND DISCUSSION}

Analysis of vertical wind profile and Theta e $(\theta \mathrm{e})$ for thunderstorms days (August and September of 2012 and 2013). The information in Fig. 3 presents the vertical profile of zonal wind over Kano for thunderstorm days in the month of August and September 2012 which show that the wind from near the surface up to $850 \mathrm{mb}$ is Westerly and it changes direction around $800 \mathrm{mb}$ and later became Easterly. The convective instability expected to overcome CIN was now taken between 925 and $850 \mathrm{mb}$ levels and Africa Easterly Jet (AEJ) can also be seen very clearly in Fig. 3 and it explains the likely experience of thunderstorm observed in August which might be as a result of $\mathrm{AEJ}$ which is a rainfall produce mechanism (Nicholson, 2009; Farnsworth et al., 2011). Figure 4 is the is the vertical profile of zonal wind over Kano thunderstorm days in 2013 (August and September) it revealed that the wind is Westerly near the surface and changes direction around $800 \mathrm{mb}$ and the wind is fluctuating between Westerly and Easterly which implies that the wind is weak compared to the vertical profile of zonal wind in Fig. 4.

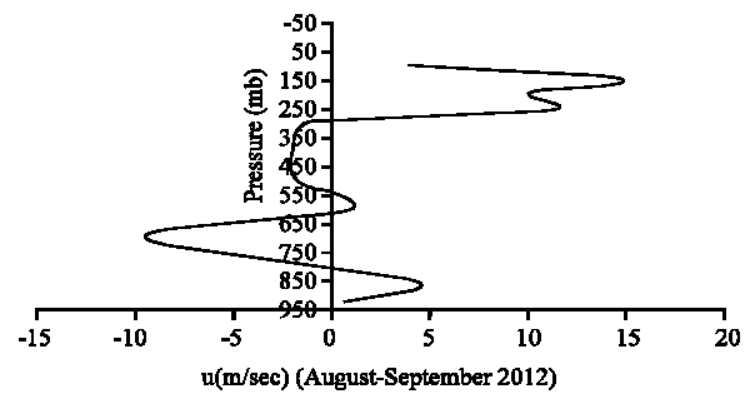

Fig. 3: Atypical vertical zonal wind profile over Kano for thunderstorm days in the months of August and September, 2012

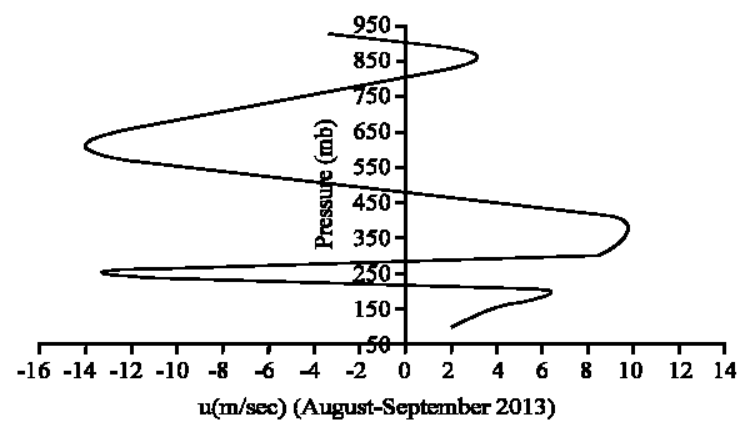

Fig. 4: A typical vertical zonal wind profile over Kano for non-thunderstorm day in the months of August and September, 2013 


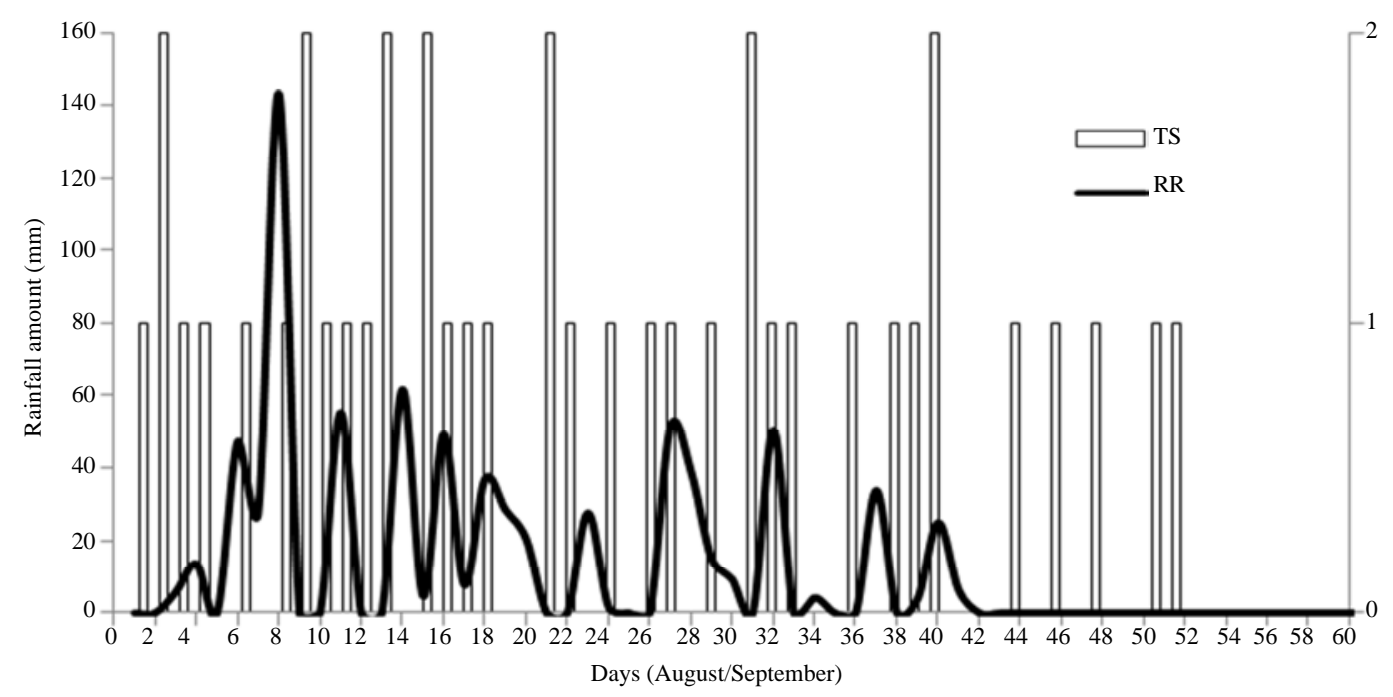

Fig. 5: Time series of thunderstorm occurrences and rainfall amount over Kano (August and September, 2012)

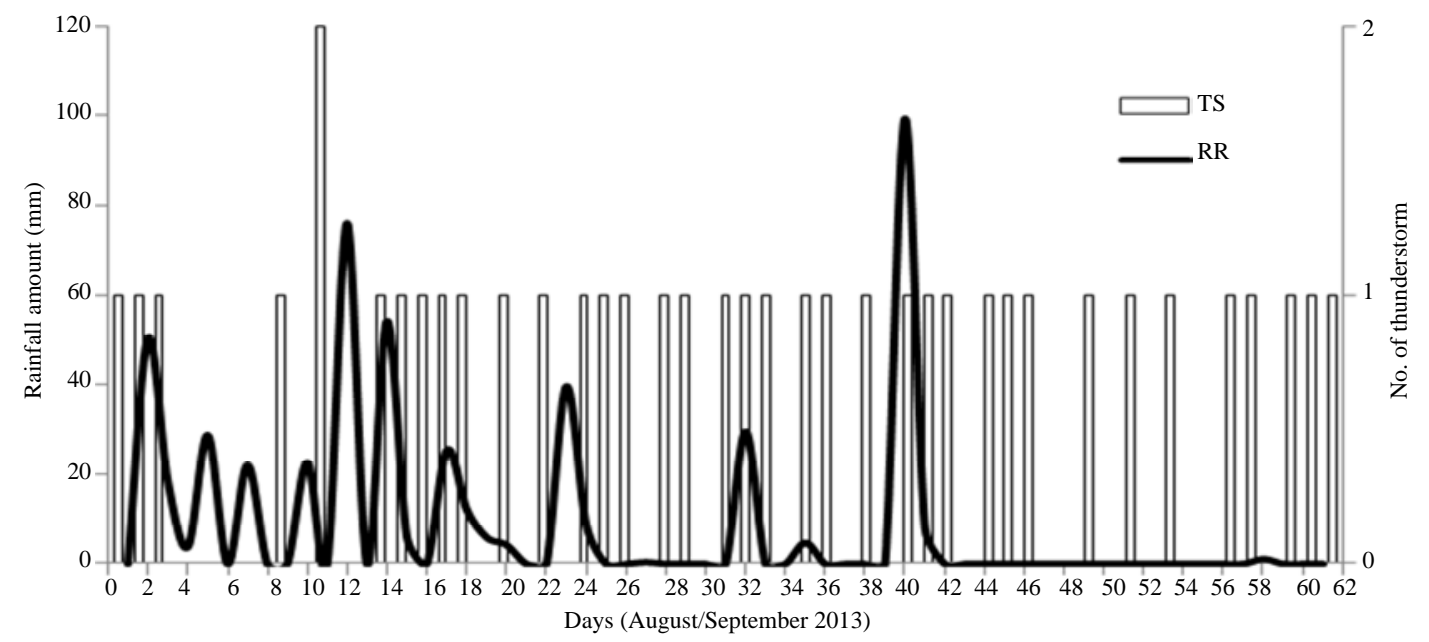

Fig. 6: Time series of thunderstorm occurrences and rainfall amount over Kano (August and September, 2013)

Figure 5 is the time series of thunderstorm occurrences and rainfall amount over Kano for August and September, 2012, the result shows that the rainfall reaches the maximum with value of $140 \mathrm{~mm}$ on 8 th of August, 2012 and thunderstorm occurred almost all days in that month and rainfall amount dropped around 11 th of September and thunderstorm occurrence continued till around 23rd of September, 2012. Figure 6 present the time series of thunderstorm occurrences and rainfall amount over Kano for August and September, 2013, rainfall reached its peaks around 10th of August and on 12th in the month of September, 2013 and thunderstorm occurred in most days in both months.

This study used a $2 \times 2$ contingency table and some associated simple skill scores such as Accuracy (AC),
Bias (B), False Alarm Ratio (FAR), Probability of Detection (POD), Probability of False Detection (POFD), Success Ratio (SR) to forecast thunderstorm occurrences over Kano (Capozzi et al., 2016). Table 2 summarised all the 16 cases that were observed in this study which aid to achieve the set objective of the research. The forecast threshold was developed for different cases, cases 1 and 2 is when the CI is $\geq 140 \mathrm{hpa}^{-1}$ between 925 and $850 \mathrm{mb}$ for August and September, 2012 respectively, cases 3 and 4 is when CI is $\geq 60 \mathrm{hpa}^{-1}$ between 700 and $500 \mathrm{mb}$ pressure level for August and September, 2012, respectively cases 5 and 6 is when the CI is $\geq 140 \mathrm{hpa}^{-1}$ between 925 and $850 \mathrm{mb}$ pressure level for August and September 2013, respectively cases 7 and 8 is when the CI threshold value is $\geq 60 \mathrm{hpa}^{-1}$ between 700 and 
Table 2: Summary of the simple skill scores from all the contingency tables Cases/skill

\begin{tabular}{lcccccc} 
score & ACC & BIAS & POD & FAR & POFD & SR \\
\hline 1 & 0.57 & 0.84 & 0.61 & 0.27 & 0.50 & 0.73 \\
2 & 0.62 & 1.00 & 0.70 & 0.30 & 0.50 & 0.70 \\
3 & 0.57 & 1.10 & 0.78 & 0.31 & 1.00 & 0.63 \\
4 & 0.55 & 0.90 & 0.54 & 0.40 & 0.44 & 0.60 \\
5 & 0.52 & 1.20 & 0.69 & 0.43 & 0.70 & 0.56 \\
6 & 0.76 & 0.94 & 0.82 & 0.12 & 0.50 & 0.87 \\
7 & 0.78 & 1.20 & 0.91 & 0.21 & 0.42 & 0.78 \\
8 & 0.61 & 1.40 & 0.93 & 0.36 & 1.00 & 0.63 \\
9 & 0.88 & 1.07 & 0.92 & 0.13 & 0.40 & 0.86 \\
10 & 0.63 & 1.70 & 1.00 & 0.42 & 0.70 & 0.57 \\
11 & 0.62 & 0.64 & 0.45 & 0.30 & 0.20 & 0.71 \\
12 & 0.54 & 1.20 & 0.80 & 0.36 & 1.00 & 0.63 \\
13 & 0.65 & 0.64 & 0.57 & 0.10 & 0.16 & 0.80 \\
14 & 0.70 & 1.00 & 0.72 & 0.27 & 0.33 & 0.72 \\
15 & 0.55 & 0.54 & 0.36 & 0.33 & 0.22 & 0.66 \\
16 & 0.56 & 0.14 & 0.86 & 0.38 & 1.00 & 0.61 \\
\hline
\end{tabular}

$500 \mathrm{mb}$ pressure level for August and September 2013 respectively, cases 9 and 10 is when the CAPE is $\geq 2500$ $\mathrm{J} / \mathrm{kg}$ for the month of August and September 2012, respectively cases 11 and 12 is when the CAPE is $\geq 2500 \mathrm{~J} / \mathrm{kg}$ for August and September 2013, respectively cases 13 and 14 is the combination of CAPE and CI when the CAPE is $\geq 2500 \mathrm{~J} / \mathrm{kg}$ and $\mathrm{CI}$ is $\geq 100 \mathrm{hpa}^{-1}$ for August and September 2012, respectively finally, cases 15 and 16 is when the CAPE is $\geq 2500 \mathrm{~J} / \mathrm{kg}$ for August and September 2013, respectively.

From the above Table 2, the study show that the level of agreement between the forecast and the observed (as represented by observations) that is accuracy in all the cases being observed in this research more than $50 \%$ were correctly predicted and in some of the threshold in few cases more than $70 \%$ were correctly predicted (Capozzi et al., 2016), for example, cases 6,7,9 and 14. The result also shows that in some cases, the bias of forecast from the observed thunderstorm and squall line were over-estimated for example in case 3 by $10 \%$ and also in cases 7 and 8 the thunderstorm forecast was over-estimated by 20 and $40 \%$, respectively. In few cases, the results also show that there is no bias. In other word there was neither an under-forecast nor over-estimated for example in cases 2 and 14 where the bias is equal to one. From the study, few cases also show that there was an under-estimation of thunderstorm and squall line occurrence in relation to convective instability, for example in case 1 where the forecast under-estimated by $16 \%$ and also in case 11 and 15 the forecasts were under-estimated by 36 and $46 \%$, respectively. The hits rate or the probability of detection in almost all the observed cases were correctly predicted that is in most cases the forecast was more than $50 \%$ correctly predicted except in case 15 where the probability of detection is $36 \%$ which implies that roughly one-third of the observed thunderstorm events were correctly predicted. The fraction of the forecasts of the event associated with non-occurrences as the name implies and is defined by false alarm ratio the result shows that in roughly of the overall forecast of the thunderstorm events, thunderstorm was actually not observed (i.e., thunderstorm did not occur) in some cases where the conditions are met that is threshold value is in place, thunderstorm was actually not occur. The probability of false detection which ranges from $0-1$ in almost all the cases being observed in this research work, the false alarm rate is between zero and one $(0$ and 1$)$. In cases $3,8,12$ and 16 where there was perfect score that is the probability of false detection is one which implies perfect score (Haley, 2016). It was also deduced from the study that the probability of success is greater than the probability of failure which implies that in all the cases there is no one that is $>1$. When the result is $<1$, the probability of success is greater than the probability of failure.

\section{CONCLUSION}

This research investigates the role of Convective Instability (CI) and Convective Available Potential Energy (CAPE) in the occurrence of thunderstorms and squall line over Kano. Daily upper air data for August and September for years, 2012 1st 2013 were used for the analysis. The CI was used to investigate the strength of instability over a layer between 925 and $850 \mathrm{mb}$ levels and also at the mid-level, the strength of the instability was also investigated between 700 and $500 \mathrm{mb}$ pressure level. It is believed that convective inhibition should be overcome before an air parcel can assess the CAPE. The study determined the relationships between convective instability and thermo-dynamical parameters in thunderstorms forecasting. More so, this research determined the threshold values of Stability Indices and Thermo-dynamical Parameters (SITPS) for the thunderstorm prediction. This research also examined the possibility of short-range forecasting of the occurrence of thunderstorms from the stability and thermodynamic parameters. In summary, the suitability of stability index in forecasting thunderstorm over the study area is investigated using contingency tables based mainly on analysis of daily upper air data over active weather period of 2 years. Consequently, the study reveals that if the CI is $\geq 100 \mathrm{hpa}^{-1}$ and CAPE is $2500 \mathrm{~J} / \mathrm{kg}$ and above, then the probability of thunderstorm occurrence is high.

\section{ACKNOWLEDGEMENT}

Researcher would like to thank the Nigerian Meteorological Agency (NIMET) for providing upper air 
data as well as Federal University of Technology Akure, Nigeria and University of Fort Hare, Alice South Africa for creating an enabling environment for research.

\section{REFERENCES}

Adedokun, J.A., 1982. On an instability index relevant to precipitation forecasting in West Africa. Meteorology Atmos. Phys., 31: 221-230.

Adelekan, I.O., 1998. Spatio-temporal variations in thunderstorm rainfall over Nigeria. Intl. J. Climatol., 18: 1273-1284.

Akinsanola, A.A. and K.O. Ogunjobi, 2014. Analysis of rainfall and temperature variability over Nigeria. Global J. Hum. Social Sci. Geogr. Environ. Geosci., 14: $1-18$.

Azorin-Molina, C., S. Tijm, E.E. Ebert, S.M. Vicente-Serrano and M.J. Estrela, 2014. Sea breeze thunderstorms in the eastern Iberian Peninsula Neighborhood verification of HIRLAM and HARMONIE precipitation forecasts. Atmos. Res., 139: 101-115.

Berz, G., W. Kron, T. Loster, E. Rauch and J. Schimetschek et al., 2001. World map of natural hazards-a global view of the distribution and intensity of significant exposures. Nat. Hazard., 23: 443-465.

Budnuka, A.C., 2015. Statistical analysis of seasonal temperature variation and thunderstorm activity over YOLA North-East Nigeria. Am. J. Educ. Res., 3: 873-880.

Capozzi, V., E. Picciotti, V. Mazzarella, G. Budillon and F.S. Marzano, 2016. Hail storm hazard in urban areas: Identification and probability of occurrence by using a single-polarization X-band weather radar. Hydrol. Earth Syst. Sci., 1: 1-22.

Davis, R.E. and R.F. Rogers, 1992. A synoptic climatology of severe storms in Virginia. Prof. Geogr., 44: 319-332.

DeRubertis, D., 2006. Recent trends in four common stability indices derived from US radiosonde observations. J. Clim., 19: 309-323.

Ekwe, M.C., J.K. Joshua, J.E. Igwe and A. Osinowo, 2014. Mathematical study of monthly and annual rainfall trends in Nasarawa State, Nigeria. IOSR. J. Math., 10: 56-62.

Farnsworth, A., E. White, C.J. Williams, E. Black and D.R. Kniveton, 2011. Understanding the Large Scale Driving Mechanisms of Rainfall Variability over Central Africa. In: African Climate and Climate Change, Williams, C. and D. Kniveton (Eds.). Springer, Dordrecht, The Netherlands, ISBN: 978-90-481-3841-8, pp: 101-122.
Fuelberg, H.E. and D.G. Biggar, 1994. The preconvective environment of summer thunderstorms over the Florida Panhandle. Weather Forecasting, 9: 316-326.

Gubenko, I.M. and K.G. Rubinshtein, 2015. Analysis of the results of thunderstorm forecasting based on atmospheric instability indices using the WRF-ARW numerical model data. Russ. Meteorol. Hydrol., 40: 16-24.

Haley, R.E., 2016. Forecast verification of the Current Icing Potential (CIP) to predict lightning hazards at US spaceports. MSC Thesis, Embry-Riddle Aeronautical University, Arizona, USA.

Hart, J.A. and A.E. Cohen, 2016. The challenge of forecasting significant tornadoes from June to October using convective parameters. Weather Forecasting, 31: 2075-2084.

Huntrieser, H., H.H. Schiesser, W. Schmid and A. Waldvogel, 1997. Comparison of traditional and newly developed thunderstorm indices for Switzerland. Weather Forecasting, 12: 108-125.

Jacovides, C.P. and T. Yonetani, 1990. An evaluation of stability indices for thunderstorm prediction in Greater Cyprus. Weather Forecasting, 5: 559-569.

Madala, S., A.N.V. Satyanarayana, C.V. Srinivas and B. Tyagi, 2016. Performance evaluation of PBL schemes of ARW model in simulating thermodynamical structure of pre-monsoon convective episodes over kharagpur using STORM data sets. Pure Appl. Geophys., 173: 1803-1827.

Moore, J.T., F.H. Glass, C.E. Graves, S.M. Rochette and M.J. Singer, 2003. The environment of warm-season elevated thunderstorms associated with heavy rainfall over the central United States. Weather Forecasting, 18: 861-878.

Mounkaila, M.S., B.J. Abiodun and J.B. Omotosho, 2015. Assessing the capability of CORDEX models in simulating onset of rainfall in West Africa. Theor. Appl. Climatol., 119: 255-272.

Mugalavai, E.M., E.C. Kipkorir, D. Raes and M.S. Rao, 2008. Analysis of rainfall onset, cessation and length of growing season for Western Kenya. Agric. Forest Meteorol., 148: 1123-1135.

Nicholson, S.E., 2009. A revised picture of the structure of the monsoon and land ITCZ over West Africa. Clim. Dyn., 32: 1155-1171.

Odekunle, T.O., E.E. Balogun and O.O. Ogunkoya, 2005. On the prediction of rainfall onset and retreat dates in Nigeria. Theor. Appl. Climatol., 81: 101-112. 
Omotosho, J.B., 1985. The separate contributions of line squalls, thunderstorms and the monsoon to the total rainfall in Nigeria. Intl. J. Climatol., 5: 543-552.

Paulikas, M.J. and W.S. Ashley, 2011. Thunderstorm hazard vulnerability for the Atlanta, Georgia metropolitan region. Nat. Hazards, 58: 1077-1092.

Ricard, D., V. Ducrocq and L. Auger, 2012. A climatology of the mesoscale environment associated with heavily precipitating events over a northwestern Mediterranean area. J. Appl. Meteorol. Climatol., 51: 468-488.

Serkov, A., S. Nikitin, V. Kravchenko and V. Knyazev, 2015. Thunderstorm hazards early warning system. Proceedings of the 2nd International Scientific-Practical Conference on Problems of Infocommunications Science and Technology (PIC S\&T'15), October 13-15, 2015, IEEE, Kharkiv, Ukraine, ISBN:978-9-6697-5192-8, pp: 137-138.

Taszarek, M., H.E. Brooks and B. Czernecki, 2017. Sounding-derived parameters associated with convective hazards in Europe. Mon. Weather Rev., 145: 1511-1528.
Tinmaker, M.I.R., K. Ali and S.D. Pawar, 2010. Thunderstorm electrical parameters vis-a-vis rainfall and surface air temperatures over a tropical inland station, Pune, India. J. Meteorol. Soc. Japan. Ser. II, 88: 899-908.

Vujovic, D., M. Paskota, N. Todorovic and V. Vuckovic, 2015. Evaluation of the stability indices for the thunderstorm forecasting in the region of Belgrade, Serbia. Atmos. Res., 161: 143-152.

Wasula, A.C., L.F. Bosart and K.D. LaPenta, 2002. The influence of terrain on the severe weather distribution across interior Eastern New York and Western New England. Weather Forecasting, 17: 1277-1289.

Wieczorek, G.F., M.C. Larsen, L.S. Eaton, B.A. Morgan and J.L. Blair, 2001. Debris-flow and flooding hazards associated with the December 1999 storm in coastal Venezuela and strategies for mitigation (No. 2001 144). Master Thesis, United States Geological Survey, Reston, Virginia, USA.

You, W., Z. Zang, X. Pan, L. Zhang and Y. Li, 2015. Statistical analysis of thunderstorms on the eastern Tibetan Plateau based on modified thunderstorm indices. Adv. Atmos. Sci., 32: 515-527. 